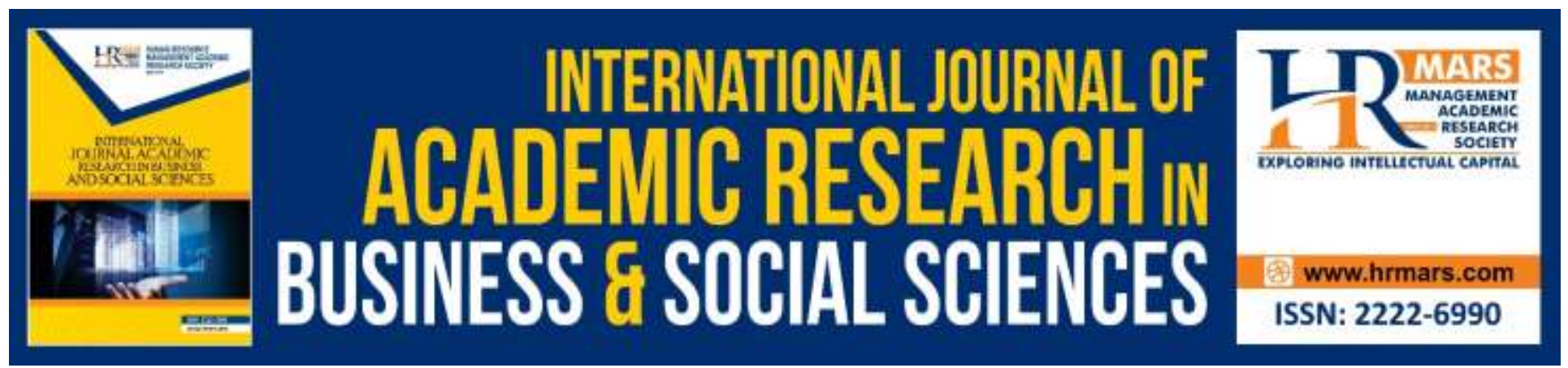

\title{
The Effect of Differentiated Instruction on EFL Learners: Teachers' Perspective
}

\author{
Ibrahim Magableh, Amelia Abdullah
}

To Link this Article: http://dx.doi.org/10.6007/IJARBSS/v10-i5/7235

DOI:10.6007/IJARBSS/v10-i5/7235

Received: 09 March 2020, Revised: 11 April 2020, Accepted: 21 April 2020

Published Online: 28 May 2020

In-Text Citation: (Magableh \& Abdullah., 2020)

To Cite this Article: Magableh, I., \& Abdullah., A. (2020). The Effect of Differentiated Instruction on EFL Learners: Teachers' Perspective. International Journal of Academic Research in Business and Social Sciences, 10(5), 626-641.

Copyright: (C) 2020 The Author(s)

Published by Human Resource Management Academic Research Society (www.hrmars.com)

This article is published under the Creative Commons Attribution (CC BY 4.0) license. Anyone may reproduce, distribute, translate and create derivative works of this article (for both commercial and non-commercial purposes), subject to full attribution to the original publication and authors. The full terms of this license may be seen at: http://creativecommons.org/licences/by/4.0/legalcode

Vol. 10, No. 5, 2020, Pg. 626 - 641

http://hrmars.com/index.php/pages/detail/IJARBSS

JOURNAL HOMEPAGE

Full Terms \& Conditions of access and use can be found at http://hrmars.com/index.php/pages/detail/publication-ethics 


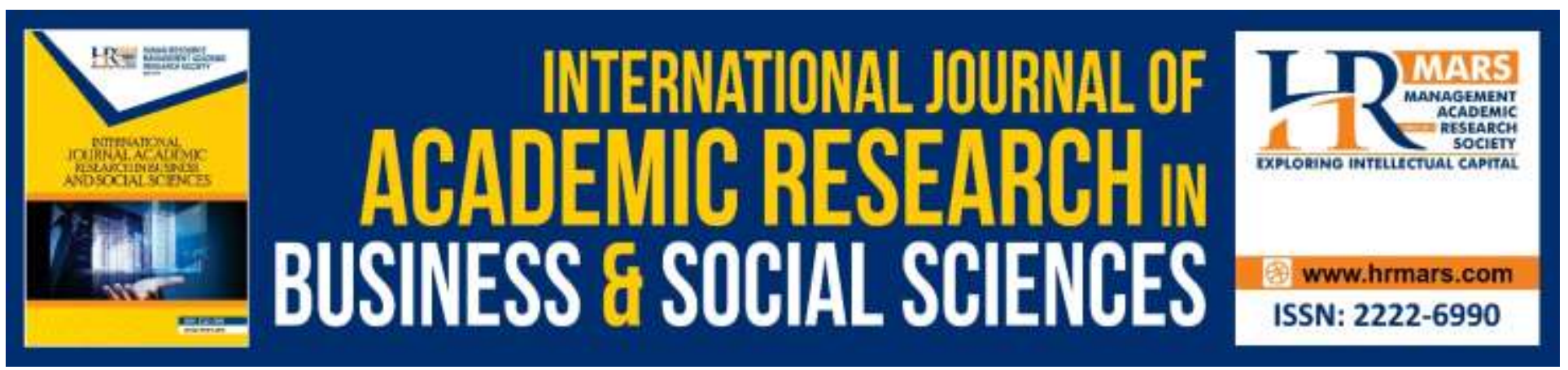

\title{
The Effect of Differentiated Instruction on EFL Learners: Teachers' Perspective
}

\author{
Ibrahim Magableh, Amelia Abdullah. \\ USM-University Sains Malaysia, 11800 USM, Gelugor, Penang. \\ Email:magablehibrahim@yahoo.com, amelia@usm.my
}

\begin{abstract}
The study investigated the effect of differentiated instruction implementation on students' learning and the challenges that face its implementation. The sample consisted of 60 grade 6 respondents randomly distributed into two groups. The experimental group $N=(30)$ was taught English following differentiated instruction strategies of flexible grouping, tiered assignment and tiered instruction in the areas of content, process and product. However, the control group $\mathrm{N}=(30)$ was taught English traditionally following the one-size-fits-all method. Moreover, 42 English teachers who were teaching elementary grades from grades 1-9 in one of Irbid districts which is called, Taibeh, distributed in 14 schools, formed the population of the study. Fourteen teachers were interviewed to answer the two questions of the study. The researchers followed a mixed-method design in which both a quantitative method which was a pretest/ posttest and a qualitative method which was a semi-structured openended interview with teachers were used to answer the questions of the study. T-test results revealed that there was a statistical significant difference between the two groups favoring the experimental group. Planning for differentiated activities, the lack of resources and the lack of administration's support were the most common challenges of differentiated instruction's implementation.
\end{abstract}

Keywords: Differentiated Instruction, Learning, Teachers, Perspectives, Differentiation.

\section{Introduction}

Today's classrooms are diverse and the idea that students learn in different ways is not new (Magableh \& Abdullah, 2020). Students differ in various ways and the idea of one-size-fits-all is no longer acceptable in today's classrooms (Dixon, Yessel, McConnell \& Hardin, 2014; Tomlinson, 2014; Tomlinson \& Imbeau, 2010). Today's classrooms have struggling learners, accelerated ones, the disabled, the talented, the auditory, the kinesthetic, visual learners and students from different cultures and backgrounds who vary in their interests, readiness, needs and development (De Graaf, Westbroek, \& Janssen, 2019; Tompkins, 2014). In order for teachers to meet this diversity in mixedability classrooms, they should modify their instruction to meet all the students' different needs. Differentiated instruction is a useful approach of teaching which allows teachers to adjust their teaching by taking into consideration learners' conditions and variabilities (Said \& Ehsan, 2019). Students are not the same in terms of getting knowledge although they are in the same age group, and teachers should not teach them in the same way, in the one-size-fits-all method (Bondie, Dahnke, 
INTERNATIONAL JOURNAL OF ACADEMIC RESEARCH IN BUSINESS AND SOCIAL SCIENCES Vol. 10, No. 5, May, 2020, E-ISSN: 2222-6990 @ 2020 HRMARS

\& Zusho, 2019). Teachers should modify and adjust the curriculum, the instruction, the methods, and the products for the group of learners. Tomlinson (2014) stated that differentiation is the teacher's proactive response to learners' needs.

Anstee (2014) defines differentiated instruction as modifying a lesson, or parts of it to suit one, some or all learners. Tomlinson (2017) mentions that distinguished instruction is a philosophy in which teachers tailor teaching to meet students' needs. Separated education can be in four areas: in the content, process, product and learning environment based on students' readiness, interests and learning profile. Tomlinson (2014) defines each area of differentiated instruction. The content is information and ideas that students need to learn to reach the learning goals. The process is how students take in and know the content; it is the way the teachers teach and the learners learn. The product is how students show what they have learnt. The environment is the climate and the physical and mental tone of the classroom. Readiness is the previous knowledge about the specified learning goals. Interests are the passion, the kinship and the empathies that motivate learning. And finally, the learning profile is the preferred approaches to learn (Gardner, 2018).

Separated instruction is not a new philosophy. It has roots to Vygotsky's the Zone of Proximal Development (ZPD) and to Bloom's Taxonomy, (Anstee, 2014; Dixon, Yessel, McConnell \& Hardin, 2014; Morgan, 2014; Subban, 2006; Tomlinson \& Imbeau, 2010, Magableh \& Abdullah, 2020). Vygotsky (1978) states that the ZPD is the distance between what students can do alone without help, and what they can do with the help of adults. The teachers would design lesson to challenge all levels, just above the current level of the students building on what students' know and encourage students to go to a zone where they could not cross without the teachers' help. Bloom's Taxonomy has also roots in differentiated instruction. Teachers plan according to it where the low-level students can do activities in remembering, and understanding or knowledge and comprehension domains (Kotob, \& Abadi, 2019). The average class level can do activities in application and analysis, while the above-average students can do activities in synthesis and evaluation (Forehand, 2010). Teachers should be familiar to the strategies of differentiated instruction and should understand that students' diversity is a good thing. Stronge (2018) states that effective teachers play great roles in developing students' learning. One of the important roles of teachers in distinguished instruction is to know learners and provide suitable education to meet individual needs (Moosa, \& Shareefa, 2019). Teachers should recognize the feeling of the students and be responsive to situations and students' needs. In this study the researcher is trying to find out whether differentiated instruction affects students' learning and the challenges that teachers face in its implementation in one of Irbid districts in Jordan.

\section{Literature Review}

A lot of researches were conducted on students to discover the effect of differentiated instruction strategies in mixed-ability classrooms. However, very few took Jordan as the context of the study. Moreover, teachers are the most important element in succeeding differentiated learning implementation and their perspectives are very important as its implementation. To some teachers, mixed-ability classrooms are a source of worry because of the presence of the below-average or the low achievers (Kotob \& Abadi, 2019). As a reflex to the mixed-ability classrooms, many educators supported the idea of streaming students into different classes. They supported the idea of putting the slow learners in separate groups to take care of such students' learning needs and provide the right support (Towers, Taylor, Tereshchenko, \& Mazenod, 2019). However, in mixed-ability classrooms, all levels are sitting side by side in the same room regardless of their proficiency level. A 
sizable number of studies of whose native language is English investigated the effectiveness of differentiated instruction on students' learning like Aftab, 2015; Ashton, 2018; Dixon, Yessel, McConnell \& Hardin, 2014; Kotob \& Abadi, 2019; Pentimoti, Justice, Yeomans-Maldonado, McGinty, Slocum \& O'connell, 2017; Stavrou and Koutselini, 2016; Suprayogi, Valcke, \& Godwin, 2017. However, few investigated the effect of differentiated instruction on Jordanian context like Magableh \& Abdullah, 2019; Magableh \& Abdullah, 2020; Siam \& Al-Natour, 2016).

Dixon, Yessel, McConnell and Hardin (2014) investigated the relationship between modified instruction in one side and professional development and teachers' efficacy in the other side. The sample consisted of 41 Caucasian teachers from both genders. The researchers used self-efficacy scale and a questionnaire that focuses on differentiated instruction. The findings indicated that the teachers who had greater self-efficacy beliefs apply differentiated instruction more. Besides, the greater professional development the teachers get, the more self-efficacy beliefs the teachers have. The results showed that the more ability to teach students effectively, the more possible to differentiate. The study also revealed that differentiated instruction is a practical way to meet students' individual needs. In the process of differentiated instruction, professional development and self-efficacy are important as the results indicated.

Aftab (2015) surveyed teachers' beliefs about implementing differentiated instruction in the classrooms. The sample consisted of 120 middle school level teachers who were surveyed to find out their attitudes toward differentiated instruction. The finding revealed a positive attitude toward implementation of differentiated learning and teachers' beliefs and opinions. The upshots also discovered that all participants wanted to apply differentiated instruction. The conclusion revealed short of planning for differentiation.

Siam and Al-Natour (2016) investigated the differentiated teaching practices and the challenges that teachers of Jordan face when implementing differentiated instruction. The aim is to identify the differentiated instruction (DI) practices in the areas of content, methods, product, assessment, and learning environment. The sample consisted of 194 teachers participated in the mixed-method designs. The main instruments of the study were a quantitative survey followed by qualitative interview with the teachers. The findings indicated that the implementation of modified instruction was very low. However, the implementation of differentiated instruction was statistically noteworthy in the private schools over public schools. Moreover, the results indicated the weak support from administration, low family support, shortage of time, and absences in learning resources were among the most common challenges.

Stavrou and Koutselini (2016) investigated differentiation of teaching and learning and the teachers' perspective toward differentiation. The study aimed to discover teachers' perspectives toward differentiated instruction in mixed-ability classrooms and to scrutinize separated instruction regarding reading abilities of students and their attitudes toward learning. The researcher followed 4 tools to collect data, the pre-test/post-test, students' interviews, classroom observation and teachers' diary records. The findings revealed that the main obstacles for differentiation are how to define, analyze, and hierarchize reading abilities from the simplest to the most complex. Moreover, the study also revealed challenges like how to identify readiness, design lessons' activities to address readiness, interests and learning profiles, and flexible grouping. The findings revealed that differentiated instruction contributes positively to students' self-efficacy and learning, and teachers' 
INTERNATIONAL JOURNAL OF ACADEMIC RESEARCH IN BUSINESS AND SOCIAL SCIENCES

Vol. 10, No. 5, May, 2020, E-ISSN: 2222-6990 @ 2020 HRMARS

cooperation with others has a major role to implement differentiation according to students' learning needs.

Pentimonti et al. (2017) studied whether the teachers implement high support or low support of differentiated language instruction. The study aimed to investigate the dynamic processes that teachers use when applying lesson plans which need scaffolding. Thirty-seven pre-school teachers and 177 children participated in the study. The researchers followed the observation method by using cam recorders and videotapes to record the frequent usage of scaffolding. The results revealed that teachers use scaffolding at a low rate and the low-support of scaffolding is more frequently used than the high support one. The researchers recommended making use of professional development which focuses on the dynamic types of intervention.

Suprayogi, Valcke, and Godwin (2017) studied the effect of the implementation of differentiated learning on students. The variables were teacher's self-efficacy, teaching experience, certificate, classroom size, teachers' beliefs and professional development. The sample consisted of 604 teachers from 145 Indonesian schools. Four types of tools were used, a questionnaire, and three scales of beliefs, implementation of differentiated instruction and efficacy. The results showed that differentiated instruction implementation is high but below the global benchmarks. Moreover, the results showed that the licensed teachers showed higher implementation to differentiated instruction compared to those who do not hold education license. The results also indicated that the class size affected differentiated instruction and the need to differentiate instruction goes side by side with the class size.

Ashton (2018) investigated the New Zealand teachers' views toward multi-level language classrooms. The researcher followed two methods of study, quantitative and qualitative ones. The quantitative was a survey, while the qualitative was teachers' interviews about multi-level classrooms. Sixty-three language teachers formed the sample of this study. The findings indicated that the majority of teachers do not feel reinforced in their schools. The study also discovered that the teachers had got no sufficient professional development. The finding also revealed that multi-level classes are hard to deal with and the increase in teachers' workloads negatively affected their happiness and students' grades as a result.

Kotob and Abadi (2019) examined distinguished instruction strategies implementation on English language achievement of below-average and above-average in a mixed-ability classroom. It investigates the strategies used by a teacher to apply some strategies of differentiated learning in mixed-ability classrooms. A total of 20 respondents from one mixed-ability classroom were the sample of the experimental study that was conducted on 10 below-average and 10 above-average respondents. To get the data, pre-test and post-test were used as the instrument to gauge belowaverage's and the above-average's academic achievement. In the experiment, the researchers used separated instruction as the experiment. The findings indicated that the experimental class was able to develop their academic score from pre-test to post-test. The results revealed a noticeable improvement in the below-average's academic scores following the implementation of differentiated instruction. But for the above-average, the difference is insignificant between the pre-test and posttest following the employment of this process.

Magableh and Abdullah (2019) explored the effect of differentiated instruction on $7^{\text {th }}$ graders' reading comprehension achievement. Through a mixed-method design, the researchers followed the quantitative and the qualitative methods to collect data. The sample consisted of a whole section of grade $7, \mathrm{~N}=28$ for the experimental group which was taught following differentiated instruction of 
flexible grouping, leveled assignment and tiered instruction. The control group is another class of grade $7, \mathrm{~N}=27$ which was taught in one-size-fits-all method. The finding showed that there was a statistical significant difference favoring the experimental group which indicated that differentiated instruction helped students' reading comprehension achievement.

Teachers in Jordan are not differentiating instruction in a structured way; differentiation is at the lowlevel and the most dominant teaching method is the one-size fits-all (Siam \& Al-Natour, 2016; Magableh \& Abdullah, 2020). The district of Taibeh, where the current study takes place, contains seven male and another seven female schools that apply differentiated instruction strategies. Differentiated instruction as Siam and Al-Natour (2016) discovered is not applied in most Jordanian public schools and if applied, it is at minimal limit in most public schools in Jordan. Few studies investigated the effect of differentiated instruction on students' learning in the district concerned in this study. This study will try to find out the effect of modified instruction and discover the challenges of its implementation through a mixed-method design from teachers' perspectives. When applying differentiated instruction in Jordanian public schools, teachers of Jordan are facing many obstacles. The researchers are trying to add more literature about teachers' perspective towards differentiated instruction to see whether it affects students' learning and the most common challenges that Jordanian teachers are facing when implementing differentiated instruction in public schools of Jordan. The main objectives of this current study is,

- To find out the effect of differentiated instruction implementation on elementary EFL learners in Jordan.

- To find out the challenges that teachers of public schools in Jordan are facing when applying differentiated instruction in mixed-ability classrooms.

This study tries to answer the following questions:

1/Does differentiated instruction implementation affect elementary EFL learners in Jordan?

2/What are the challenges teachers of public schools in Jordan are facing in differentiated instruction's implementation in mixed-ability classrooms?

The null hypothesis is set forth which stated that there is no statistical significant difference at $(\alpha<0.05)$ between the experimental and the control groups when differentiated instruction is applied.

\section{Methods}

\section{Design}

The researcher followed the explanatory sequential design where the quantitative data is followed by the qualitative and both were used to answer the questions of the study. The first design was the pretest/posttest for both groups at the onset and at the end of the treatment. The second instrument was an open-ended semi-structured interview with 14 English teachers who are teaching grades 1- 9 in Taibeh district in the year 2019/2020. The instruments were validated by showing them to two university instructors in Yarmouk University, to the three English supervisors in Taibeh district and to three English teachers outside the sample to see whether the questions of the test are suitable to grade 6 and to check difficulty, time suitability and the test relatedness to content. The researchers took the panel's recommendation into consideration and did the amendments accordingly. Moreover, the researchers ensured the test reliability by piloting it into a whole section of grade 6 $\mathrm{N}=(26)$ from the same population but outside the sample. The test-retest was applied twice within a two weeks period. Pearson's correlation coefficient was calculated and found to be 0.87 . Correlation coefficient is a value between -1 and +1 . Matthews (2019) indicates that correlation above 0.7 is strong. The researchers considered 0.87 value is a strong value to ensure reliability of the test. The 
interview protocol questions were also presented to the panel to see whether they are suitable to elementary teachers. Later after the interviews, the results of the interview were validated and made reliable by inter-rater reliability by comparing the results with an external validator who is a proficient in qualitative data analysis and by taking them to the interviewees to discuss with them to ensure result validity. Inter-rater reliability was found to be $k=0,76$, which is considered substantial reliability. All the interviews were recorded and the interview protocol was applied to make sure whether all interviewee understood all the questions of the interview. The interview protocol contained some probing questions to explain the main questions. The interviews expanded over three days and each one lasted between 10 to 12 minutes. The data were analysed qualitatively depending on hand analysis method (Creswell \& Creswell, 2017).

\section{Participants}

The sample consisted of 60 students in two classes of grade 6 from two different male schools in Taibeh district. Two schools were randomly chosen using simple random sampling method, and one class of grade 6 was also chosen from each school following the random sampling method also. Once the two schools and the two classes were selected, they were distributed randomly into the two groups of the study. The respondents were randomly distributed into one class of 30 respondents for the experimental group which was taught following differentiated instruction, and another class of 30 respondents for the control group which was taught traditionally following the one-size-fits-all method. The population of teachers was all the male and female English teachers $N=(42)$ teachers who were teaching elementary grades from 1-9 in Al Taibeh district which includes 7 villages. The study is concerning with the elementary stage only, so teachers, who teach the secondary stage, were excluded from the population of the study. After gaining the consent of Jordan Ministry of Education and Al Taibeh District, the researcher interviewed 14 teachers based on convenience sample on voluntary basis. The experiences of the teachers in teaching grades 1 to 9 varied from 5 to 15 years. The researchers took their written consents to be part of the experiment and explained to them that they can withdraw from the interview at any time without giving explanation why they have to leave. The researchers also assured them that their responses were strictly confidential and would not be used outside the study purposes. The researchers also explained to the interviewees that their names and their schools' titles were not to be used at any part of the study.

\section{Instrument}

The researchers used two instruments. The first one is the pre/post achievement assay for both groups. It consisted of reading comprehension questions, grammar questions, vocabulary and sentence writing. The highest mark to be gained is 50 and 0 is the lowest. The pretest results were used as a placement test for the experimental group students to divide them into three homogeneous groups to supply them with tiered assignment and tired instruction. A post-test was administered at the end of the treatment to see the outcome of the treatment on both groups. The second instrument was a semi-structured open-ended interview which was prepared by the researchers for the purpose of the study. The responses of the interviewees were recorded following the interview protocol. All the interviews were conducted using English Language because all the interviewees were teachers of English and had at least a bachelor degree in English language. Later, the recordings were sent to a specialist to transcribe and change the audio and the notes taken in the interview protocol into a word document file on the computer. Then after analyzing the data qualitatively, the results were taken to the interviewees to discuss and validate the results. 


\section{Material}

The main course book was Action Pack 6 including Action Pack 6 Student Book, Action Pack 6 Activity Book as well as the Action Pack 6 Teachers' guide. Action pack is the series the Jordanian studies from grade 1 to grade 12 for English language. Besides, the experimental group was supported by supplementary materials including differentiated and leveled short stories, electronic sources and tiered reading comprehension texts from Action Pack 6 teacher's guide.

\section{Procedures}

The study started in September 2019 by getting official consent from Jordan's Ministry of Education and from Taibeh district. The researchers made the test valid and reliable and applied it to a pilot study. The researchers familiarized the experimental group teacher with the strategies of differentiated instruction in several meetings before conducting the study. The pre-test was conducted on both groups at the beginning of the study, and after 12 weeks of instruction, another achievement test was conducted. The qualitative part was the semi-structured interviews with 14 English teachers who were teaching the elementary stage in Jordan, grades from 1-9 in the first semester 2019/2020. After gaining the consent and getting the two authorization forms from the Jordanian Ministry of Education and Al Taibeh district, the researchers asked the teachers' written consent to participate in the study. The interviews took place in different days to visit the different schools upon availability of the English teachers and the researchers and were audio recorded. The audio recordings were sent to specialists to transcribe and convert them into a word document file.

\section{Data Analysis}

The results were analyzed quantitatively and qualitatively. The pre-test/post-test was analysed using descriptive statistics as well as the independent sample t-test and the effect size. The interview was analysed qualitatively using content analysis method. The responses of the interviewees were studied carefully by the two researchers, and then were analyzed to produce the results qualitatively which were used to support the data of the quantitative analysis. The data analysis process took a systematic procedure. The interviews were recorded, transcribed and written on a word document file. After making a word file, six steps were followed to produce the qualitative data, preparing and organizing data, coding data, forming themes, reporting findings, interpreting the meaning of the findings, validating the results by external validator to compare the results with the codes to ensure accuracy of the findings. The results were taken to the interviewees again to check and to gain results validity.

\section{Findings}

Table1

T-test Results of the Experimental and Control Groups on the Pre-test

\begin{tabular}{lllllll}
\hline Test & Group & $\mathrm{N}$ & Mean & Std. Dev. & $\begin{array}{l}\mathrm{T} \\
\text { value }\end{array}$ & Sig. \\
& & & & & 0.07 & 0.843 \\
\hline
\end{tabular}


INTERNATIONAL JOURNAL OF ACADEMIC RESEARCH IN BUSINESS AND SOCIAL SCIENCES

Vol. 10, No. 5, May, 2020, E-ISSN: 2222-6990 @ 2020 HRMARS

\begin{tabular}{lllll}
\hline $\begin{array}{l}\text { pre- } \\
\text { test }\end{array}$ & experimental & 30 & 19.6 & 7.30 \\
\hline
\end{tabular}

Table2

T-test Results of the Experimental and Control Groups on the Post-test

\begin{tabular}{|c|c|c|c|c|c|c|c|}
\hline test & Group & $\mathrm{N}$ & Mean & SD & T-value & Sig. & $\begin{array}{l}\text { Effect-size } \\
\text { Cohen's-d }\end{array}$ \\
\hline \multirow{2}{*}{$\begin{array}{l}\text { post- } \\
\text { test }\end{array}$} & control & 30 & 19.9 & 7.31 & \multirow[b]{2}{*}{7.81} & \multirow[b]{2}{*}{$0.000 *$} & \multirow[b]{2}{*}{2.31} \\
\hline & $\begin{array}{l}\text { experime } \\
\text { ntal }\end{array}$ & 30 & 26.6 & 5.73 & & & \\
\hline
\end{tabular}

Table 3

T-test and Effect-size Results for Grade 6 Students on the Pre and Post-test for each Group

\begin{tabular}{|c|c|c|c|c|c|c|c|}
\hline Grade 6 & Test & DF & Mean & SD & $\begin{array}{l}\mathrm{T} \\
\text { value }\end{array}$ & Sig. & $\begin{array}{l}\text { Effect size } \\
\text { Cohen's d }\end{array}$ \\
\hline \multirow{2}{*}{ Control } & pre & & 19.2 & 7.44 & \multirow{2}{*}{0.38} & \multirow{2}{*}{0.505} & \multirow{2}{*}{0.09} \\
\hline & post & 29 & 19.9 & 7.31 & & & \\
\hline \multirow[t]{2}{*}{ Experimental } & pre & & 19.6 & 7.30 & \multirow{2}{*}{6.79} & \multirow{2}{*}{$0.0001^{*}$} & \multirow{2}{*}{2.14} \\
\hline & post & 29 & 26.6 & 5.73 & & & \\
\hline
\end{tabular}

The qualitative findings of the research were presented depending on the order of the questions. The findings of question one come first, then followed by the findings of question two. The qualitative analysis which depended on the content analysis method where hand analysis was the basis and was followed to analyze the results. First, the interviews were recorded and then transcribed. After that the data were coded, segmented and categorized into the major themes. After reporting the results, the data analysis process was validated by comparing how the researchers categorized and coded the results with how an external validator did it (Hayashi Jr, Abib, \& Hoppen, 2019). The researchers compared their codes and categories with the inter-rater codes and categories as a measure of validity and reliability. Cohen's Kappa was found to be $\mathrm{K}=0,76$ which was considered a substantial agreement between the inter-raters. The results were validated by taking them back to the interviewees to discuss whether their responses match the results.

Question one findings indicated that differentiated teaching affects students' learning positively. Four major themes appeared from the interviewees' responses to the first question on why differentiated instruction effected students' learning positively. The themes were, differentiated instruction helps all levels; it allows students to work based on their proficiency level; differentiated instruction increases motivation, and helps strugglers to feel that they are no longer weak.

Regarding the first theme, differentiated instruction helps all levels: the below-average, average and the above-average students. Interviewee1 indicated "differentiated instruction helps all kinds of learners inside the classroom, especially the low achievers who benefit more. Differentiating the content, the process and the product affects students' learning." Other responses from interviewees do not differ from interviewee 1. Interviewee 7 explained that "All learners can achieve better in learning when applying differentiated instruction. The above-average can extend their knowledge and the below-average can develop learning." Interviewee 5 stated, "All students benefit from differentiated instruction if it is fully applied. One condition to achieve better learning through 
INTERNATIONAL JOURNAL OF ACADEMIC RESEARCH IN BUSINESS AND SOCIAL SCIENCES

Vol. 10, No. 5, May, 2020, E-ISSN: 2222-6990 @ 2020 HRMARS

differentiation is that, teachers should be aware of differentiated strategies and fully apply them on students."

The second theme was separated instruction helps students to work within their proficiency level, which will help academic achievements in all English skills and not just the overall score. The results showed that when working with different ability levels in class, students will develop different kinds of skills. Interviewee 12 explained that "Through differentiated instruction, students work within their levels and that is an advantage not to feel that it is too difficult or too easy. Interviewee 14 remarked that "When applying differentiating instruction, many students work based on their levels and that will help to develop their levels. Interviewee 1 explained that "Differentiation allows students to experience instruction based on their ability, and sometimes we need to challenge this ability to develop."

The third theme was differentiated instruction increases motivation. Interviewee 9 stated that "Differentiated instruction helps students learning in that it increases motivation." Modified education makes the classroom more active and pupils become more enthusiastic to learning. Interviewee 5 reflected, "With differentiated education, students become more enthusiastic to learning because they work based on their levels. Interaction in the class increases, and students' motivation develops as well."

The fourth theme was that separated instruction helps strugglers to feel that they are no longer weak. Differentiation helps the below-average students to get rid of being shy and bridges the gap between the three levels in the class. Interviewee 10 expressed that "Through differentiated instructions, struggling students feel that they are no longer be seen as weak students." Interviewee 3 explained that "Differentiated instruction helps to increase confidence in that the weak students can answer questions as good as the above-average." When the below-average students are given the chance to work based on their pace, they will achieve something, and then they might move to the next level. Interviewee 8 expressed that "The below-average students can move to the next level, and their achievement will be increased when they feel that they are part of the class and their learning matters. This way, they will feel that they are not strugglers."

The second question's findings indicated 5 themes regarding the challenges that teachers are facing when modified instruction is applied. The challenges are common among all the interviewees. The five themes were planning; fixed curriculum and textbook; the heavy load the teachers are taking and the number of students in the classrooms; the lack of differentiation strategies due to the lack of professional development regarding differentiated instruction strategies, and finally the lack of resources and the insufficient support from administrations.

The first theme regarding the second question was planning. Planning rose as a problem which hinders differentiated instruction implementation. Teachers have to plan three lesson plans for each class to match the three levels. Interviewee 2 explained that "The major difficulties are planning, specially designing the tasks and the content, and the lack of the data availability". Planning for differentiation takes much time, which consumes teachers' own private time. Interviewee 4 expressed that "timing for planning is the most common challenge to implement differentiated instruction". He stated that "Planning for a long time is a major problem. Planning for a good differentiated lesson will take over 4 hours at home and that will consume all my effort. If there were ready plans from administrators, it will be easier."

The second theme was fixed curriculum and textbook. One of the major challenges is that teachers are only to teach from the textbook and they have to finish a certain amount of material each day. They have a predesigned curriculum from the ministry of education that they have to follow which 
INTERNATIONAL JOURNAL OF ACADEMIC RESEARCH IN BUSINESS AND SOCIAL SCIENCES Vol. 10, No. 5, May, 2020, E-ISSN: 2222-6990 @ 2020 HRMARS

hinders differentiated instruction implementation. Interviewee 8 explained that "We are committed to a pre-planned textbook which prevents us from getting outside materials or even to choose materials to some students. Besides, all students should get all the materials, if not; the teachers will be responsible for not giving the syllabus." Interviewee 11 stated that "If we have the chance to choose certain amount from outside textbooks, then differentiated instruction will be very consistent." The third theme was the heavy load the teachers are taking and the number of students in the classrooms. The teachers of Jordan, as an average, teach 24 classes a week and class size ranges from 27 to 35 students in most classes. Teachers are taking over 5 to 6 classes a day, so this is a heavy load for teachers and one of the major challenges to apply differentiation. Interviewee 3 remarked "I have 24 periods a week, that means five classes a day and to apply differentiation in all the periods will be very difficult in terms of planning." Interviewee 6 stated "some classes are over 35 students with a small room; it is very difficult to plan and differentiate to meet all levels. It is difficult to follow them up with differentiated instruction.

The fourth theme was the lack of differentiation strategies teachers know due to the lack of professional development regarding differentiated instruction strategies. Nearly all teachers expressed that they lack the modified learning strategies because the professional development they attend was not taking differentiation into consideration. Interviewee 1 and 10 explained that the lack of professional development regarding differentiated instruction is a real and a major obstacle. Interview 1 stated that "The Ministry of Education did make some professional development but not regarding differentiated instruction strategies. I mean if we want to apply it in the perfect way, we should be trained on the strategies." Interviewee 10 stated that "Differentiated instruction is a new topic to them; they read about it, but they were not being trained sufficiently how to use it."

The last theme was the lack of resources and the inadequate support from administrations. Not all public schools are well-equipped with the all resources the teachers need. Some schools lack the textbooks themselves, and they need the technological devices which are major components to differentiated instruction. Interviewee 6 indicated that "the lack of resources and the lack of support from administration form a challenge for applying differentiated instruction correctly." Interviewee 10 explained that "Our school does not have recorders or computers in the classrooms. Those tools are needed to implement differentiated instruction." Some administrations are critical when they see that the class moves, or when they see movements inside the classrooms. In applying differentiated instruction, sometimes, the class voices get high that leads the administration and other teachers to think that the teachers who apply differentiation have a problem in classroom management. Interviewee 8 explained that "Because voices get high, I do not apply differentiated instruction constantly because the administration will think I am sitting doing nothing and children are playing. This is a major problem hindering differentiated instruction implementation."

\section{Discussion}

Two classes of grade 6 were randomly selected to investigate the effect of differentiated instruction implementation on students' EFL achievement in Jordan. As shown in Table 1, the mean score of the experimental group on the pre-test was 19.6 and of the control group 19.2. The independent sample t-test was calculated to check the homogeneity of the two groups and see whether the difference in the mean score was statistically significant. T-value was found to be 0.07 and the significant $P$ was 0.843 . The computed $P$-value was greater than the level of significance $P<0.05$. This indicates that the difference in the pre-test mean scores was insignificant, and thus the two groups were homogeneous at the beginning of the treatment. The post-test results indicated that the experimental group's mean score was 26.6 which was higher than control group mean score which was 19.9. T-test was 
considered to see if this difference is statistically significant. As illustrated in Table 2, the independent sample t-test was found to be 7.81 and P-value was 0.000 which was below the significant level $\mathrm{P}<0.05$. This designates that differences in the mean scores between the two groups were statistically significant. Therefore, the null hypothesis is rejected and the researchers concluded that differentiated instruction affected students' EFL achievement. The experimental group respondents outperformed their counterparts of the control group.

Comparing the results of each group, as shown in Table 3, there was a difference between the pretest and the post-test of the control group. The mean score of the pre-test was 19.2, and 19.9 in the post-test. The difference between the two mean scores was statistically insignificant; P-value was 0.505 which was above $\mathrm{P}<0.05$ the level of significance. Compared to the experimental group, the pre-test mean score was 19.6 before the outset of the experiment and became 27.5 after the experiment. The difference was statistically significant under $P<0.05$. Distinguished instruction, as shown from the results, affected grade 6 students' EFL achievement in Jordan. A significant notice shown by the findings of grade 6 results was related to the standard deviation (SD). The experimental group standard deviation was 7.30 before the treatment and reduced to 5.73 on the post-test. However, standard deviation of the control group was 7.44 on the pre-test and 7.31 on the post-test. This signposts that differentiated instruction did not only develop students' EFL achievement, but also reduced the students' diversity in mixed-ability classroom to be more homogeneous. However, nearly no change took place to decrease the range of students in the control group. Moreover, the effect size was calculated using Cohen's formula to calculate the difference between the means of the two groups. Wilcox (2019) explains that a value of 0.2 represents a small effect size, and 0.5 has a medium one, and 0.8 has a large effect size. The effect size presented in (Table 3), 2.14 was a high effect size indicating that differentiated instruction was effective in increasing students' EFL achievement. Conversely, the control group's effect size was 0.09 which shows that the one-size-fitsall had a minimal and limited influence on students' EFL achievement.

The finding indicated that distinguished learning affects students' learning positively. The quantitative results showed statistical significant differences between the two groups favoring the experimental group. Moreover, the qualitative results were in consistent with the quantitative ones. The qualitative findings explain why student benefited from differentiated instruction. All the interviewees remarked that differentiated instruction affects learning in the four skills and not just in one skill and for all students' levels with more mentioning the low-level students, or below-average students. Differentiated instruction as indicated from the finding helps all class levels because all of them are working on their own pace and level. The below-average are working, and they no longer see themselves as inferior to their mates from average or above-average because differentiated instruction grants them the confidence that allow to answer questions as any other students in the class. The above-average students are challenged by activities which are not easily done, and they no longer see themselves as demotivated if they are given tasks as the below-average students. The struggler students are no longer seen as strugglers because they worked on a level in which they can achieve with trust and confident. The reasons why differentiation helps improve students' learning, as the study revealed, were because differentiated instruction increases students' motivation, increases interaction, and allows each student to work on his or her own pace and interests. Differentiated instruction allows the low-level students to get engaged in learning and to find learning possible while they always consider it impossible. 
INTERNATIONAL JOURNAL OF ACADEMIC RESEARCH IN BUSINESS AND SOCIAL SCIENCES Vol. 10, No. 5, May, 2020, E-ISSN: 2222-6990 @ 2020 HRMARS

The results also showed that EFL Jordanian teachers face many challenges when implementing differentiated instruction which leads them not to differentiate constantly. The findings revealed that the teachers lack the strategies of differentiated instruction because of the absence of professional development related to it. Administrators also lack the ideas of differentiated instruction strategies as indicated from the study finding which hinders its implementation in schools of Jordan. Moreover, the study revealed that the timing to plan for differentiation takes too long as teachers have heavy load exceeding 24 periods a week which is considered very difficult to plan for differentiated lessons. If differentiated instruction is planned carefully, then teachers will find it possible to achieve and will get better results with students. Reducing the teachers' heavy loads provides more time for teachers to plan for differentiated instruction inside the school, and they will not consume their time outside the school time. Another finding is that differentiated instruction was affected negatively by the size of the class. The researchers think that the bigger the class is, the more we need to differentiate and the more we need to deal with individual differences. However, the findings showed that having 35 students in one class makes it difficult to differentiate and to follow up all students in mixed-ability classrooms. The study revealed that the teachers who apply differentiation are having difficulties in its implementation. Triangulating qualitative data with the quantitative results confirms that differentiated instruction helped students' EFL achievement. To fulfil external validity, the researcher also confirmed validity of the data analysis process by showing the data to an external inter-rater with the list of codes and categories. The researchers compared their codes with inter-rater codes. Besides, the researcher ensured the results validity by showing the results with the interviewees to confirm their responses with the findings. The findings of the qualitative data are in line with and confirm the finding of the quantitative data.

The results of this study are in line with Dixon, Yessel, McConnell and Hardin (2014), Magableh and Abdullah (2019) and Magableh and Abdullah (2020)'s findings in that differentiated instruction affects students' learning. The results of this study are in consistent with Siam and Al-Natour (2016)'s findings in the challenges of implementing differentiated instruction like the weak support from administration, the shortage of time and planning, and absence of learning resources. The results are also in agreement with Suprahyoid, Valcke, and Godwin (2017)'s finding in that the class size affects implementing differentiated instruction. Kotob and Abadi (2019)'s results showed that differentiated instruction affected students' achievement as the results of the current study.

\section{Conclusion}

In conclusion, all of the responses and the findings of the study suggest that differentiated instruction affects students' learning positively. Applying differentiated instruction in mixed-ability classrooms has many positive aspects like increasing motivation, promoting interaction, improving students' proficiency level and enhancing the overall achievement. Although there are a few challenges in differentiated instruction implementation like planning, the class size, the number of students in the classroom, the shortage of support from administrations and the lack of professional development, the interviewees were positive that these challenges can be minimized and reduced with professional development and more knowledge about differentiated instruction strategies. The quantitative findings from the first question indicated that differentiated instruction has a direct impact on students' learning and that was validated by the qualitative findings. The qualitative findings of the first question support and explain the quantitative findings. Using mixed-method design for this study is an attempt to see alternative techniques of framing differentiation regarding whether to implement differentiated instruction or not despite the challenges that teachers face. Many 
researchers are gradually accepting quantitative and qualitative method to explain the results. The practical implications of the current study will contribute to educational variations by helping decision makers and educators in Jordan to help teachers to appreciate the important role of distinguished instruction in Jordanian EFL classrooms. Another implication of the study is that the Jordanian Ministry of Education should focus on teachers' professional training on differentiated instruction before and while service. It is proved from this study that teachers of Jordan are facing difficulties which hinder differentiated instruction implementation. The education department in universities should teach separated education materials and train the expected teachers on how to apply differentiation strategies. The Ministry should pave the way to minimize if cannot remove all of these obstacles. This study will add to existing literature information and data about the effect of a new method to implement in EFL classrooms which proved to improve achievements in mixed-ability classrooms.

The researchers would like to recommend the administrations to urge teachers to implement differentiation constantly. Even if teachers have a fixed text books to cover, still they can differentiate by tiered activities. Teachers can differentiate the product when different types of products can be presented by students to show and demonstrate their learning. If teacher cannot differentiate the content, they can differentiate the process of learning where flexible grouping can solve the problem of having very crowded classrooms. Differentiation is not just one strategy to follow, teachers can pick from so many to suit their students. However, more investigations should be made to discover the effect of differentiated instruction on more variables and in different contexts. Investigation should also be made on whether differentiated instruction affects individual skills. The researcher would recommend applying a whole professional development program on differentiated instruction application to enable Jordanian teachers to deal with different proficiency levels in one classroom. Further studies including large number of participants are recommended. Longitudinal experimental studies over longer periods of time will gain better and more accurate results. More studies on differentiation on different school levels like the secondary stage can give more insight about its applications. Finally, more studies to investigate differentiated instruction on specific skills like the effect on reading fluency, writing, grammar, or speaking will examine how differentiation affects the four skills. The finding of this study is limited to the small sample where only two sections of grade 6 and only 14 male and female teachers participated in the study. Besides, the study finding is limited in the sampling techniques where convenient sample was used to interviews. Finally, the study is limited to the instrument where only two instruments are used.

\section{Conflict of interest}

The authors declare that there are no any conflicts of interest regarding publication of this study. This research is not funded by any organization that might cause conflict.

\section{Acknowledgment}

The researchers would like to thank the board of education and the teachers involved for their support during the research.

\section{References}

Aftab, J. (2015). Teachers' Beliefs about Differentiated Instruction in Mixed Ability Classrooms\&58; a Case of Time Limitation. Journal of Education and Educational Development, 2(2), 94-114. Anstee, P. (2014). Differentiation Pocketbook. Management Pocketbooks. 
INTERNATIONAL JOURNAL OF ACADEMIC RESEARCH IN BUSINESS AND SOCIAL SCIENCES

Vol. 10, No. 5, May, 2020, E-ISSN: 2222-6990 @ 2020 HRMARS

Ashton, K. (2018). Exploring teacher views of multi-level language classes in New Zealand secondary schools. Teaching and Teacher Education, 69, 104-118.

Bondie, R. S., Dahnke, C., \& Zusho, A. (2019). How Does Changing “One-Size-Fits-All” to Differentiated Instruction Affect Teaching? Review of Research in Education, 43(1), 336-362.

Creswell, J. W., \& Creswell, J. D. (2017). Research design: Qualitative, quantitative, and mixed methods approaches. Sage publications.

De Graaf, A., Westbroek, H., \& Janssen, F. (2019). A Practical Approach to Differentiated Instruction: How Biology Teachers Redesigned Their Genetics and Ecology Lessons. Journal of Science Teacher Education, 30(1), 6-23.

Dixon, F. A., Yssel, N., McConnell, J. M., \& Hardin, T. (2014). Differentiated instruction, professional development, and teacher efficacy. Journal for the Education of the Gifted, 37(2), 111-127.

Forehand, M. (2010). Bloom's taxonomy. Emerging perspectives on learning, teaching, and technology, 41(4), 47-56.

Gardner, H. (2018). Multiple approaches to understanding. In Contemporary Theories of Learning (pp. 129-138). Routledge.

Hayashi Jr, P., Abib, G., \& Hoppen, N. (2019). Validity in Qualitative Research: A Processual Approach. The Qualitative Report, 24(1), 98-112.

Kotob, M. M., \& Abadi, M. A. (2019). The Influence of Differentiated Instruction on Academic Achievement of Students in Mixed Ability Classrooms. International Linguistics Research, 2(2), p8-p8.

Magableh, I., \& Abdullah, A. (2019). The effect of differentiated instruction on developing students' reading comprehension achievement. International Journal of Management and Applied Science (IJMAS), 5 (2), 48-53.

Magableh, I. S. I., \& Abdullah, A. (2020). On the Effectiveness of Differentiated Instruction in the Enhancement of Jordanian Students' Overall Achievement. International Journal of Instruction, 13(2), 533-548.

Matthews, K. (2019). Using Mixed-Methods Analysis to Study Political Self-Efficacy. SAGE Publications Ltd.

Moosa, V., \& Shareefa, M. (2019). The Impact of Teachers' Experience and Qualification on Efficacy, Knowledge and Implementation of Differentiated Instruction. International Journal of Instruction, IJI, 12(2), 587-604.

Morgan, H. (2014). Maximizing student success with differentiated learning. The Clearing House: $A$ Journal of Educational Strategies, Issues and Ideas, 87(1), 34-38. Oaks CA: SAGE.

Pentimonti, J. M., Justice, L. M., Yeomans-Maldonado, G., McGinty, A. S., Slocum, L., \& O'connell, A. (2017). Teachers' use of high-and low-support scaffolding strategies to differentiate language instruction in high-risk/economically disadvantaged settings. Journal of Early Intervention, 39(2), 125-146.

Said, M., \& Ehsan, N. (2019). The Effects of Differentiated Instruction on Students' Language Attitude and Critical Thinking in an ESL Context (Doctoral dissertation, University of Sheffield).

Siam, K., \& Al-Natour, M. (2016). Teacher's Differentiated Instruction Practices and Implementation Challenges for Learning Disabilities in Jordan. International Education Studies, 9 (12), 167.

Stavrou, T. E., \& Koutselini, M. (2016). Differentiation of Teaching and Learning: The Teachers' Perspective. Universal Journal of Educational Research, 4(11), 2581-2588.

Stronge, J. H. (2018). Qualities of effective teachers. ASCD. 
INTERNATIONAL JOURNAL OF ACADEMIC RESEARCH IN BUSINESS AND SOCIAL SCIENCES

Vol. 10, No. 5, May, 2020, E-ISSN: 2222-6990 @ 2020 HRMARS

Subban, P. (2006). Differentiated instruction: A research basis. International education journal, 7(7), 935-947.

Suprayogi, M. N., Valcke, M., \& Godwin, R. (2017). Teachers and their implementation of differentiated instruction in the classroom. Teaching and Teacher Education, 67, 291-301.

Tomlinson, C. A. (2014). The differentiated classroom: Responding to the needs of all learners. Ascd.

Tomlinson, C. \& Imbeau, M. (2010). Leading and Managing a differentiated classroom. Alexandria, VA: Association for Supervision and Curriculum Development.

Tomlinson, C. A. (2017). How to differentiate instruction in academically diverse classrooms. ASCD.

Tompkin, G. (2014). Literacy for the $21^{\text {st }}$ century: A balanced approach. Pearson USA.

Towers, E., Taylor, B., Tereshchenko, A., \& Mazenod, A. (2019). 'The reality is complex': teachers' and school leaders' accounts and justifications of grouping practices in the English key stage 2 classroom. Education 3-13, 1-15.

Vygotsky, L. S. (1978). Mind in society: The development of higher psychological processes. Cambridge, MA: Harvard University Press.

Wilcox, R. (2019). A Robust Nonparametric Measure of Effect Size Based on an Analog of Cohen's d, Plus Inferences about the Median of the Typical Difference. Journal of Modern Applied Statistical Methods, 17(2), 1. 